Article

\title{
"Intrinsic" Anion Exchange Polymers through the Dissociation of Strong Basic Groups: PPO with Grafted Bicyclic Guanidines
}

\author{
Riccardo Narducci ${ }^{1}$, , Gianfranco Ercolani ${ }^{2}$, Raul Andres Becerra-Arciniegas ${ }^{1,3}$, \\ Luca Pasquini $^{3}{ }^{-1}$, Philippe Knauth ${ }^{3, *}$ and Maria Luisa Di Vona ${ }^{1, *}$ \\ 1 Dep. Industrial Engineering, and International Associated Laboratory: Ionomer Materials for Energy, \\ University of Rome Tor Vergata, 00133 Roma, Italy; riccardo.narducci@uniroma2.it (R.N.); \\ raul-andres.becerra-arciniegas@univ-amu.fr (R.A.B.-A.); \\ 2 Dep. Chemical Sciences and Technologies, University of Rome Tor Vergata, 00133 Roma, Italy; \\ ercolani@uniroma2.it \\ 3 Aix Marseille Univ, CNRS, MADIREL (UMR 7246) and International Associated Laboratory: Ionomer \\ Materials for Energy, Campus St Jérôme, 13013 Marseille, France; luca.pasquini@univ-amu.fr \\ * Correspondence: philippe.knauth@univ-amu.fr (P.K.); divona@uniroma2.it (M.L.D.V.)
}

Received: 27 March 2019; Accepted: 24 April 2019; Published: 29 April 2019

\begin{abstract}
We synthesized anion exchange polymers by a reaction of chloromethylated poly(2,6-dimethyl-1,4-phenylene)oxide (PPO) with strongly basic 1,5,7-triazabicyclo[4.4.0]dec-5-ene (TBD). TBD contains secondary and tertiary amine groups in the guanidine portion. To favor the functionalization with the secondary amine, TBD was activated with butyl lithium. The yield of amine formation via the reaction of the benzyl chloride moiety with TBD was $85 \%$. Furthermore, we prepared polymers with quaternary ammonium groups by the reaction of PPO-TBD with $\mathrm{CH}_{3} \mathrm{I}$. The synthesis pathways and ionomer structure were investigated by NMR spectroscopy. The thermal decomposition of both ionomers, studied by thermogravimetry, started above $200^{\circ} \mathrm{C}$, corresponding to the loss of the basic group. The ion exchange capacities, water uptake and volumetric swelling are also reported. The "intrinsic" anion conductivity of PPO-TBD due to the dissociation of grafted TBD was in the order of $1 \mathrm{mS} / \mathrm{cm}$ ( $\mathrm{Cl}$ form). The quaternized ionomer (PPO-TBD-Me) showed an even larger ionic conductivity, above $10 \mathrm{mS} / \mathrm{cm}$ at $80^{\circ} \mathrm{C}$ in fully humidified conditions.
\end{abstract}

Keywords: ionomers; ionic conductivity; swelling; acid-base equilibria

\section{Introduction}

The development of anion exchange membranes (AEMs) for electrochemical devices, such as fuel cells, represents an important challenge for many scientists [1-6]. The main hindrances for their widespread application are low stability in alkaline conditions, poor hydrophilic/hydrophobic domain separation, the high water content needed to favor the dissociation of the ion pairs, and carbonatation issues that decrease the conductivity, just to mention a few [7-12]. These challenges seem very difficult to address, but the benefits of using AEMs justify the efforts.

AEMs are generally formed by ammonium groups grafted on a polymeric backbone. Hydroxide counter anions are responsible of the conduction and, at the same time, for the degradation of these solid-state ionic materials. The problem is complex and to simplify we can distinguish between the degradation of the polymeric matrix and the degradation of the positive ammonium groups. The most commonly used backbone is poly(2,6-dimethyl-1,4-phenylene)oxide (PPO), a commercial high-performance amorphous polymer that is easy to functionalize in order to form ionomers with a high ion-exchange capacity (IEC). Given that the IEC is inversely related to the equivalent weight (EW) 
of the polymer repeat unit, a high IEC can be achieved with a low degree of amination, because the EW of the PPO is small.

PPO is stable under basic conditions, however, the functionalization can alter the charge distribution, making the ether linkages susceptible to the hydroxide attack [13-16]. Many ammonium groups have been studied, including aromatic and aliphatic molecules linked to the matrix via short or long chains [17-21]. The $\mathrm{S}_{\mathrm{N}} 2$ reaction between the positive nitrogen and the $\mathrm{OH}^{-}$is mainly responsible for the degradation, and it is difficult to prevent $[15,22-25]$. In a recent paper, we showed that the stability of the quaternary group can be improved using a bicyclic amine (1,5-diazabicyclo[4.3.0]non-5-ene, DBN) where the delocalization of the positive charge is possible on an extended portion of the molecule [26]. However, the yield of the functionalization reaction is low, because of the high steric hindrance and the scarce nucleophilicity of DBN.

In this study, we started with chloromethylated PPO and used 1,5,7-triazabicyclo[4.4.0]dec-5-ene (usually abbreviated as TBD, IUPAC abbreviation HPP [27]) as functionalizing agent, which contains secondary and tertiary amine groups in the molecule. TBD is a strong bicyclic guanidine base (pKa $=15.2$ ) protonated in water [28], and soluble in organic media, with a high steric hindrance and the ability, when protonated, to delocalize the positive charge between nitrogens and the double bond. Guanidine bases can act as nucleophiles [27,29], however, to improve the yield of the amination reaction on the secondary nitrogen of chloromethylated PPO, TBD was activated through the reaction with butyl lithium (BuLi). The formed PPO-TBD can behave in water as an "intrinsic" anion exchange membrane due to the strong basic character of TBD. This concept is explored in this work and the properties of PPO-TBD are compared with those of the more classical quaternized PPO-TBD-Me obtained by the methylation of PPO-TBD.

\section{Experimental}

Poly(2,6-dimethyl-1,4-phenylene)oxide (PPO), 1,5,7-triazabicyclo[4.4.0]dec-5-ene (TBD) and all reagents were purchased from Sigma-Aldrich and used without further purification.

\subsection{Synthesis of Chloromethylated $\mathrm{PPO}\left(\mathrm{PPO}-\mathrm{CH}_{2} \mathrm{Cl}\right)$}

The procedure was adapted from references $[30,31]$. The degree of chloromethylation (DCM), determined by NMR spectroscopy, was 0.28 .

\subsection{Synthesis of PPO-TBD Membranes}

TBD ( $1 \mathrm{~g}, 7.5 \mathrm{meq})$ was dissolved in $10 \mathrm{~mL}$ of anhydrous THF; then $3 \mathrm{~mL}$ of a $2.5 \mathrm{M}$ solution of BuLi in hexane (7.5 meq) was added under $\mathrm{N}_{2}$ at $0{ }^{\circ} \mathrm{C}$ and stirred for $10 \mathrm{~min}$. A solution of $1 \mathrm{~g}$ of $\mathrm{PPO}-\mathrm{CH}_{2} \mathrm{Cl}(\mathrm{DCM}=0.28,7.5 \mathrm{meq})$ dissolved in $10 \mathrm{~mL}$ of anhydrous THF at room temperature under $\mathrm{N}_{2}$ was prepared separately and added to the BuLi-TBD solutions drop by drop. The resulting yellow solution was heated under stirring at $70^{\circ} \mathrm{C}$ for $24 \mathrm{~h}$. After cooling to RT, half of the solution was evaporated under vacuum and the formed solid dissolved in $20 \mathrm{~mL}$ of $\mathrm{N}$-methyl-2-pyrrolidone (NMP). The solution was evaporated in a Petri dish at $70{ }^{\circ} \mathrm{C}$ and then put in the oven for $48 \mathrm{~h}$ at $90^{\circ} \mathrm{C}$. The membrane was peeled off and washed several times in water at $60^{\circ} \mathrm{C}$ to remove the excess TBD.

\subsection{Synthesis of PPO-TBD-Me Membranes}

$\mathrm{CH}_{3} \mathrm{I}$ (1.15 mL, 18.75 meq) was added to the half solution obtained in the previous step (3.4 meq of PPO). The solution was maintained under stirring at RT for $18 \mathrm{~h}$ in $\mathrm{N}_{2}$ flux. After this time, the resulting solution was dried in the oven at $60^{\circ} \mathrm{C}$ for $5 \mathrm{~h}$ and the solid dissolved in $20 \mathrm{~mL}$ of NMP. The NMP solution was evaporated in a Petri dish at $70{ }^{\circ} \mathrm{C}$ and then put in the oven for $48 \mathrm{~h}$ at $90^{\circ} \mathrm{C}$. The membrane was peeled off and washed several times in water. 


\subsection{NMR Spectroscopy}

${ }^{1} \mathrm{H}$ NMR spectra were recorded with a Bruker AVANCE III spectrometer operating at $400 \mathrm{MHz}$. DMSO- $\mathrm{d}_{6}$ and $\mathrm{CDCl}_{3}$ were used as solvent. Chemical shifts (ppm) were referenced to tetramethylsilane (TMS).

\subsection{Thermogravimetric Analysis (TGA)}

High-resolution TGA analysis was performed with a TA Q500 apparatus (TA Instruments, New Castle, DE, USA). The samples were placed in Pt sample holders. The experiments were made under air flux between 50 and $600^{\circ} \mathrm{C}$. The maximum heating rate was $3 \mathrm{~K} / \mathrm{min}$.

\subsection{Ion Exchange Capacity (IEC)}

The IEC (in milliequivalents per g of dry polymer) was determined by potentiometric acid-base titration and by Mohr titration.

Potentiometric Acid-base Titration. Membranes were washed in deionized water at $60{ }^{\circ} \mathrm{C}$ for 7 days to remove the salts deriving from the synthetic procedure. For the PPO-TBD-Me samples, membranes were immersed $24 \mathrm{~h}$ in $2 \mathrm{M} \mathrm{KOH}$ at RT and washed in deionized water for $48 \mathrm{~h}$. After drying over $\mathrm{P}_{2} \mathrm{O}_{5}$ for $72 \mathrm{~h}$, the PPO-TBD and PPO-TBD-Me membranes were weighted and immersed in a $0.018 \mathrm{~N}$ $\mathrm{HCl}$ solution. The acidic solution was then back-titrated with $0.022 \mathrm{~N} \mathrm{NaOH}$.

Mohr Titration. For PPO-TBD and PPO-TBD-Me, the chloride forms were obtained by treating the membranes in a $1 \mathrm{M} \mathrm{HCl}$ or a $1 \mathrm{M} \mathrm{NaCl}$ solution during $48 \mathrm{~h}$, respectively. The membranes were then washed carefully with bi-distilled water to remove the excess $\mathrm{Cl}^{-}$. The $\mathrm{Cl}^{-}$anions contained in the membranes were exchanged with $\mathrm{SO}_{4}{ }^{2-}$ by immersion during 2 days in $1 \mathrm{M} \mathrm{Na}_{2} \mathrm{SO}_{4}$ solution. This solution was then titrated using $0.01 \mathrm{M} \mathrm{AgNO}_{3}$ and potassium dichromate as an indicator. The indicator was prepared by dissolving $1 \mathrm{~g}$ of $\mathrm{K}_{2} \mathrm{Cr}_{2} \mathrm{O}_{7}$ in $20 \mathrm{~mL}$ of water.

\subsection{Water Uptake}

The water uptake (WU) was determined at 25 and $60^{\circ} \mathrm{C}$ following the equation:

$$
\mathrm{WU}=100 \times \frac{\mathrm{m}_{\text {wet }}-\mathrm{m}_{\mathrm{dry}}}{\mathrm{m}_{\mathrm{dry}}}
$$

$\mathrm{m}_{\mathrm{dry}}$ is the sample mass after drying over $\mathrm{P}_{2} \mathrm{O}_{5}$ for $96 \mathrm{~h} . \mathrm{m}_{\text {wet }}$ is the sample mass after immersion in deionized water for $48 \mathrm{~h}$. For the measurements at $60^{\circ} \mathrm{C}$, the samples were introduced in closed Teflon vessels and put in a furnace at $60^{\circ} \mathrm{C}$. Before weighing, the excess water at the sample surface was carefully removed with adsorbent paper.

\subsection{Volumetric Swelling}

The $\mathrm{a}, \mathrm{b}$ and $\mathrm{c}$ dimensions of the samples before and after the immersion (wet) in water were accurately determined at RT with a micrometer. The volumetric swelling was defined as:

$$
\Delta \mathrm{V}=\frac{\mathrm{a}_{\mathrm{wet}} \cdot \mathrm{b}_{\mathrm{wet}} \cdot \mathrm{c}_{\mathrm{wet}}}{\mathrm{a} \cdot \mathrm{b} \cdot \mathrm{c}}
$$

\subsection{Ionic Conductivity}

The membranes in the $\mathrm{Cl}^{-}$form were obtained by treatment in $1 \mathrm{M} \mathrm{NaCl}$ solution for $48 \mathrm{~h}$ and then washed in deionized water. The fully humidified samples were analyzed by electrochemical impedance spectroscopy (VSP-300, Biologic science instruments, Seyssinet-Pariset, France). This analysis was performed between $1 \mathrm{~Hz}$ and $6 \mathrm{MHz}$ with a signal amplitude of $20 \mathrm{mV}$ and stainless steel electrodes inside a hermetically closed Swagelok cell. 
The resistance $\mathrm{R}$ of the membranes at $25,40,60$ and $80^{\circ} \mathrm{C}$ was obtained from a Nyquist plot by non-linear least-square fitting using an equivalent circuit composed of a series arrangement of two (resistance-constant phase elements) in parallel [32]. The ionic conductivity was calculated using Equation (3), where $\mathrm{d}$ is the membrane thickness and the electrode area $\mathrm{A}=0.28 \mathrm{~cm}^{2}$ :

$$
\sigma=\frac{\mathrm{d}}{\mathrm{R}_{\mathrm{mat}} \cdot \mathrm{A}}
$$

\section{Results and Discussion}

\subsection{Synthesis}

Figure 1 shows the reaction pathways for the synthesis of TBD-based anion exchange membranes. The amination route was a $S_{N} 2$ reaction very sensitive to the steric hindrance and to the strength of the nucleophile. To enhance its nucleophilic properties and to drive the reaction towards the formation of the tertiary amine, TBD was activated with BuLi. The negative charge in the TBD anion was able to be stabilized over the two nitrogens in the symmetrical positions 5 and 7 (Figure 1a). The alkylation of either of the two nitrogens led to the formation of only one isomer, namely PPO-TBD.

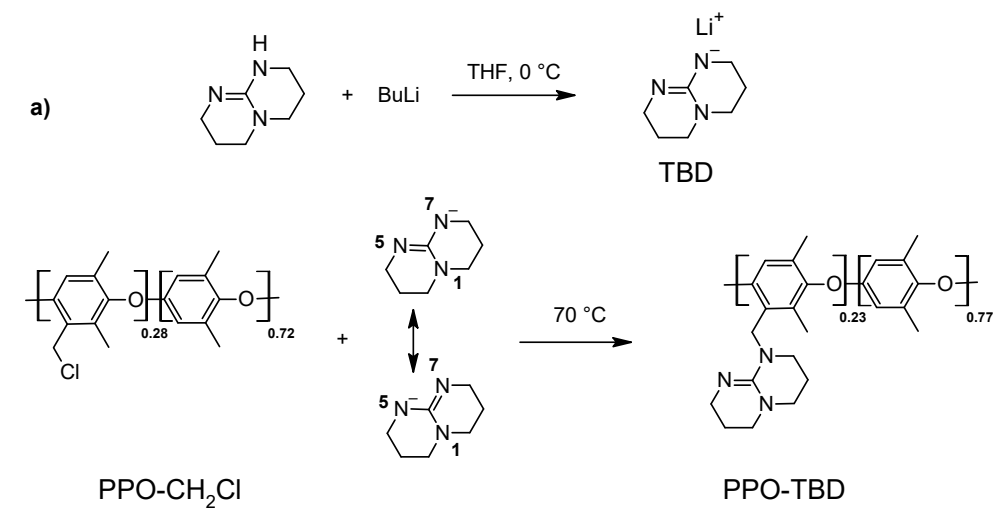

b)
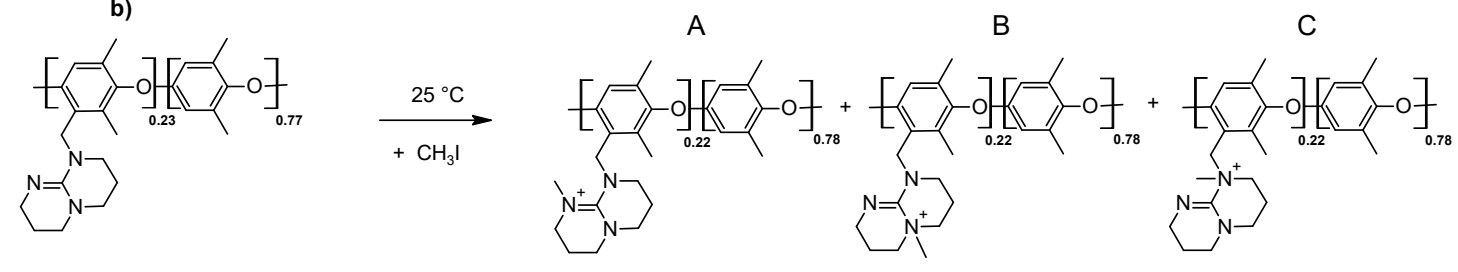

PPO-TBD-Me
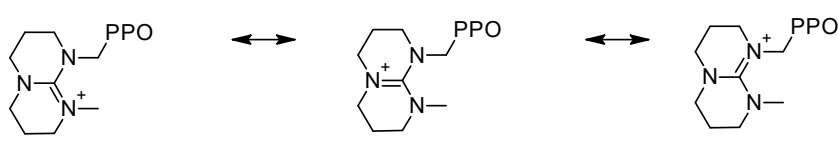

A

Figure 1. Reaction pathways for the synthesis of (a) PPO-TBD and (b) PPO-TBD-Me. The different PPO-TBD-Me isomers (A, B, and C) are represented together with the mesomeric formulas of the isomer $\mathrm{A}$.

The methylation reaction can occur on different nitrogens, leading to three different isomers (PPO-TBD-Me A, B, and C). However in only one of these (isomer A) was the stabilization of the positive charge possible (Figure $1 b$ ). This position is probably the favored position.

The NMR spectra of the precursor and products and the respective assignments are presented in Figure 2. 

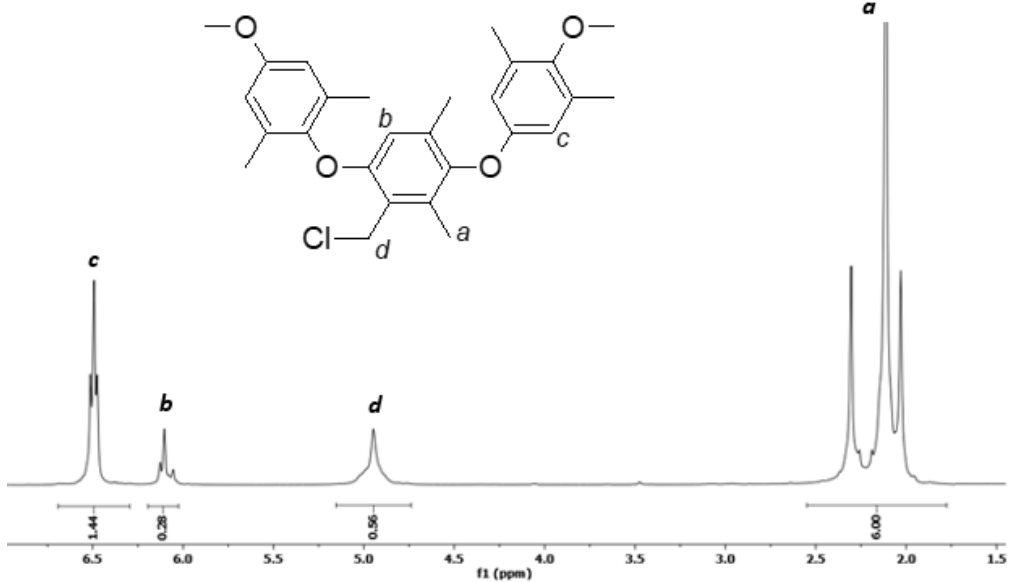

(a)

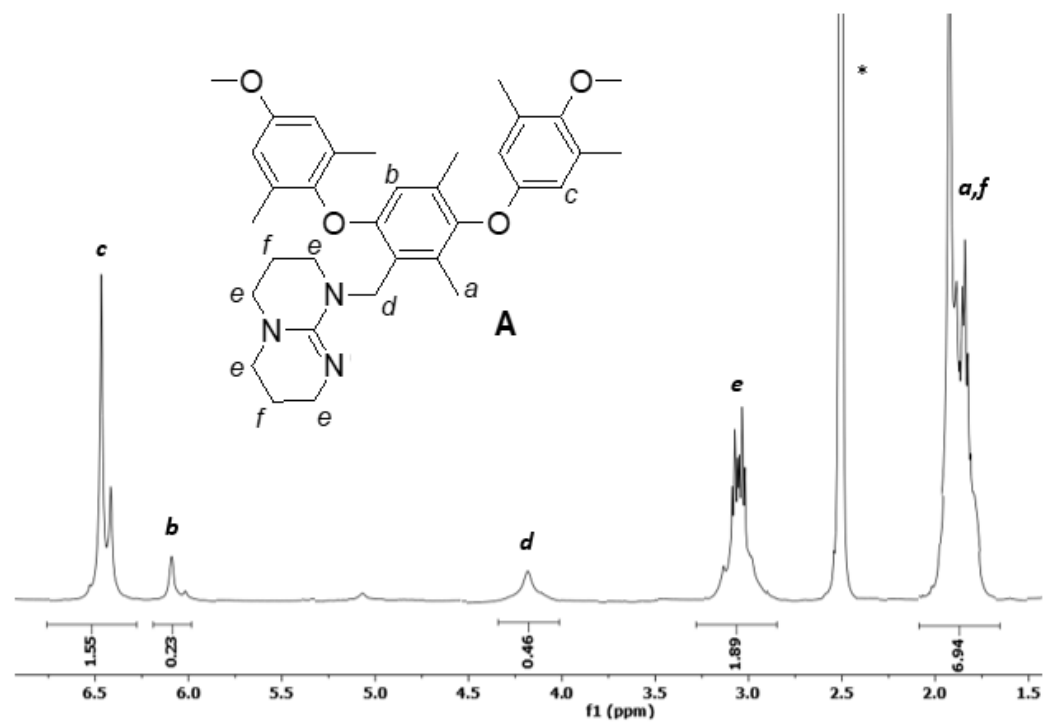

(b)

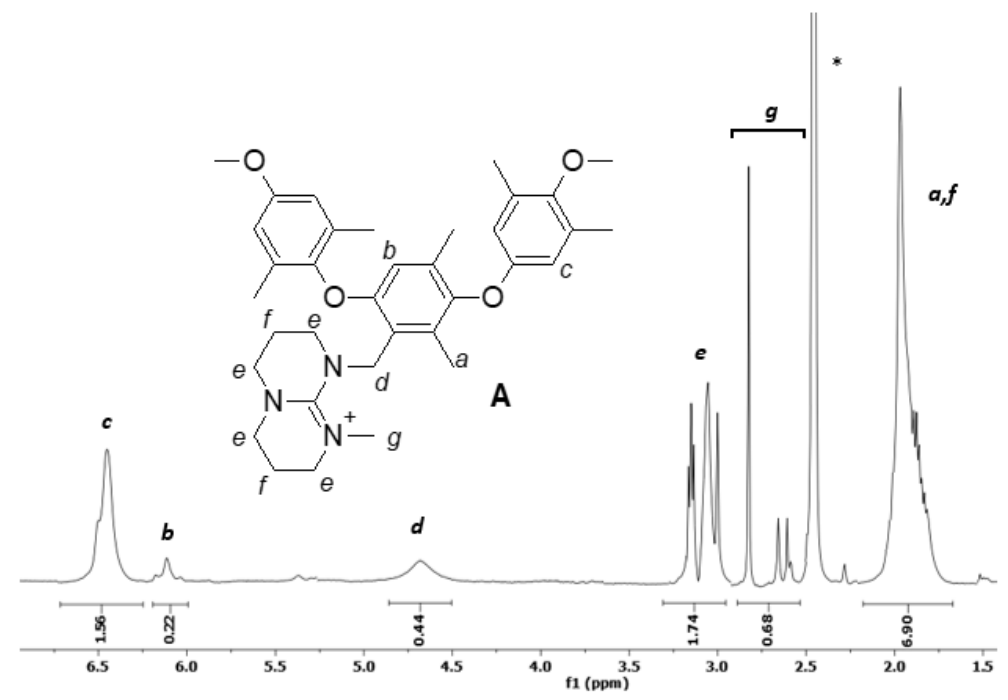

(c)

Figure 2. ${ }^{1} \mathrm{H} \mathrm{NMR}$ spectra of (a) $\mathrm{PPO}-\mathrm{CH}_{2} \mathrm{Cl}$ in $\mathrm{CDCl}_{3}$ (the solvent is not shown in the figure, 7.27 ppm), (b) PPO-TBD and (c) PPO-TBD-Me in DMSO $\left(\mathrm{d}_{6}\right)$. The asterisk indicates the solvent. 
The spectrum of PPO-C $\mathrm{C}_{2} \mathrm{Cl}$ (Figure 2a) shows the typical signals of benzylic hydrogens $(2 \mathrm{H})$ linked to chlorine atom at $4.95 \mathrm{ppm}$. The integration allowed the calculation of the degree of chloromethylation, taking as a reference the signal of the methyl groups $(6 \mathrm{H})$ on the PPO matrix $(\mathrm{DCM}=0.28)$. In the spectra of PPO-TBD and PPO-TBD-Me (Figure $2 \mathrm{~b}, \mathrm{c})$, the signals $a(6 \mathrm{H})$ and $f(4 \mathrm{H})$ overlapped. An estimation of the degree of amination was possible considering that the area of hydrogens $f$ was half that of the hydrogens $e(8 \mathrm{H})$. Subtracting the signal area $f$ from the total area of the signal centered around $2.0 \mathrm{ppm}(a+f)$, it was possible to calculate the area due to hydrogens $a$. For the spectrum 2b, this area corresponded to 5.99 hydrogens, and for the spectrum $2 \mathrm{c}$ this corresponded to 6.03 hydrogens in excellent agreement with the expected values. The degree of amination (DA), calculated from the integration of the peak $d(2 \mathrm{H})$, was equal to 0.23 for PPO-TBD and 0.22 for PPO-TBD-Me. Similar results were obtained by titrations (see below). The spectrum of PPO-TBD-Me (Figure 2c) was more complex due to the coexistence of different isomeric structures, as reported in Figure 1. The signal $g$ presented three separate peaks due to the low interconversion between the different isomeric arrangements [33]. This was confirmed by the shift of hydrogens $e$, which experience a different chemical environment. As expected, the integration indicated the presence of only one methyl group on the TBD moiety. The introduction of a further methyl group would lead to the formation of a dication. In the spectra, it was also possible to see a very small peak around 5.4 ppm due to the residual chloromethylated PPO.

\subsection{Thermogravimetry}

High resolution thermogravimetric curves for both ionomers are shown in Figure 3. The red curves indicate the quaternized PPO-TBD-Me derivative. One can observe the loss of the TBD group starting above $200{ }^{\circ} \mathrm{C}$, in agreement with data for other amines [34], followed by the loss of the methyl and chloromethyl groups with a maximum at $360^{\circ} \mathrm{C}$ [35]. The PPO main chain decomposition had a sharp maximum around $425^{\circ} \mathrm{C}$, in very good agreement with pristine PPO [35,36] and other PPO-based ionomers $[14,17]$. The black curves correspond to PPO-TBD in pristine form (continuous line) and after $168 \mathrm{~h}$ in water at $60^{\circ} \mathrm{C}$ (dashed line). The very similar shape of the curves indicates that PPO-TBD supported the prolonged treatment in water without degradation. In comparison with the quaternized ionomer, PPO-TBD presented slightly higher temperatures for the loss of TBD (maximum around $260^{\circ} \mathrm{C}$ ) and methyl and chloromethyl groups (maximum around $370{ }^{\circ} \mathrm{C}$ ). The main chain decomposition occurred with two maxima. While the second peak temperature was similar to PPO-TBD-Me $\left(425^{\circ} \mathrm{C}\right)$, the first, with a maximum around $390{ }^{\circ} \mathrm{C}$, can be attributed to in-situ cross-linked macromolecular chains. Similar cross-linking processes by radical species were previously reported in air for other PPO-based polymers [35].

\subsection{Ion Exchange Capacity (IEC)}

\subsubsection{PPO-TBD}

The acid-base titration in $0.018 \mathrm{~N} \mathrm{HCl}$, where only the most basic $\mathrm{N}$ group was protonated, provided an IEC $=1.3 \mathrm{meq} / \mathrm{g}$. The Mohr titration provided a slightly higher value of $1.6 \mathrm{meq} / \mathrm{g}$, which was however probably overestimated due to the difficult end-point detection. An average IEC $=1.4 \mathrm{meq} / \mathrm{g}$ was therefore used for the following calculations.

The theoretical relation between the IEC and the degree of functionalization DF can be written:

$$
\mathrm{IEC}(\mathrm{PPO}-\mathrm{TBD})=\frac{\mathrm{DF}}{\mathrm{M}\left(\mathrm{PPO}-\mathrm{CH}_{2}\right)+\mathrm{DF} \times \mathrm{M}(\mathrm{TBD})}
$$

The theoretical value for one protonated nitrogen is $1.62 \mathrm{meq} / \mathrm{g}$, corresponding to a degree of functionalization of the chloromethylated precursor of 0.28 . The experimental value from titration was IEC $=1.4 \mathrm{meq} / \mathrm{g}$, and according to Equation 4 corresponded to a degree of amination of 0.23 ; The NMR spectroscopy provided an according result (see above). From the comparison of the theoretical and 
experimental IEC, an amination reaction yield of $85 \%$ was deduced, which is quite high for a bulky amine like TBD.

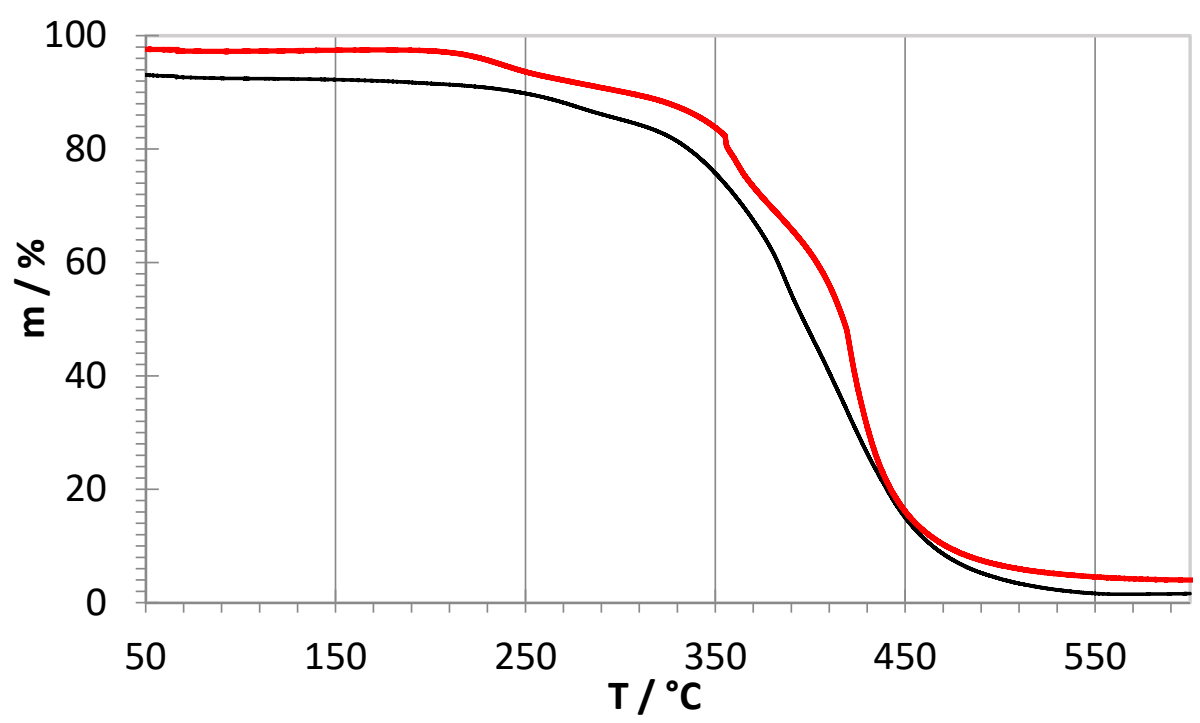

(a)

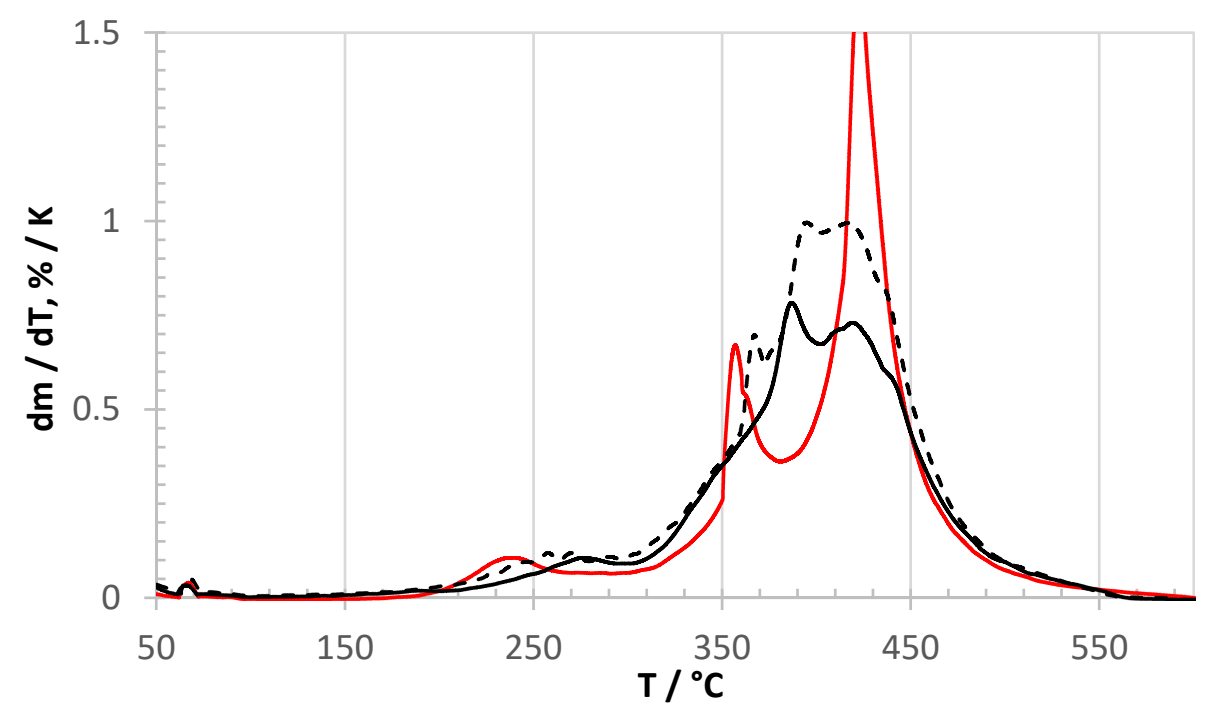

(b)

Figure 3. High-resolution thermogravimetric curves under air flow. (a) Relative mass loss (black line: PPO-TBD, red line: PPO-TBD-Me). (b) Derivative curves. Black lines: PPO-TBD (continuous: pristine, dashed: after $168 \mathrm{~h}$ in $\mathrm{H}_{2} \mathrm{O}$ at $60^{\circ} \mathrm{C}$ ); red line: PPO-TBD-Me).

\subsubsection{PPO-TBD-Me}

The IEC of the quaternized derivative in hydroxide form determined by acid-base titration was $(1.20+/-0.05) \mathrm{meq} / \mathrm{g}$. The Mohr titration of the chloride form again provided a higher value of $1.5 \mathrm{meq} / \mathrm{g}$. For the same reason as above, an IEC $=1.3 \mathrm{meq} / \mathrm{g}$ was used for the calculations. The theoretical IEC corresponding to a degree of functionalization of 0.28 was $1.58 \mathrm{meq} / \mathrm{g}$. The experimental degree of amination of 0.22 (obtained from titration and NMR) was consistent with a yield of $80 \%$, starting from the chloromethylated precursor, slightly below that for PPO-TBD, which is logical, because it also included the quaternization reaction with $\mathrm{CH}_{3} \mathrm{I}$. 


\subsection{Water Uptake and Swelling}

The water uptake WU and hydration numbers at 20 and $60^{\circ} \mathrm{C}$ can be found in Table 1 . The hydration numbers $\lambda$ were calculated using the equation:

$$
\lambda=\frac{10 \cdot \mathrm{WU}}{\mathrm{IEC} \cdot \mathrm{M}\left(\mathrm{H}_{2} \mathrm{O}\right)}
$$

There is no real contradiction between gravimetric water uptake and volumetric swelling data for the two ionomers. The relatively large volumetric swelling of PPO-TBD might be related to a lower cohesion of the polymer network, due to the absence of permanent ionic interactions. The permanent ion charges led to larger hydration numbers for PPO-TBD-Me, but with lower volumetric swelling. The larger hydration number increased the ionic conductivity (see below).

Table 1. Gravimetric water uptake WU, hydration numbers $\lambda$ and volumetric swelling $\Delta \mathrm{V}$ after $48 \mathrm{~h}$ in $\mathrm{H}_{2} \mathrm{O}$ at 20 and $60^{\circ} \mathrm{C}$ of PPO-TBD and PPO-TBD-Me.

\begin{tabular}{ccccc}
\hline Ionomer & $\mathbf{T} /{ }^{\circ} \mathbf{C}$ & $\mathbf{W U} / \%$ & $\boldsymbol{\lambda}$ & $\boldsymbol{\Delta} \mathbf{V} / \%$ \\
\hline \multirow{2}{*}{ PPO-TBD } & 20 & 19.6 & 7.8 & 74 \\
& 60 & 30.0 & 11.9 & 85 \\
\hline \multirow{2}{*}{ PPO-TBD-Me } & 20 & 32.5 & 13.9 & 44 \\
& 60 & 37.5 & 16.0 & 47 \\
\hline
\end{tabular}

\subsection{Ionic Conductivity}

TBD is a very strong base with an experimental acid constant in water $\mathrm{pK}_{\mathrm{a}}=14.5$ [34] (theoretical value: 15.2 [37]). The grafting of the TBD molecule on the PPO macromolecular chain should change the basicity only slightly. The calculated degree of dissociation, according to Figure 4 , assuming $\mathrm{pK}_{\mathrm{b}}$ $=-0.5$ was $80 \%$. The protonation occurred on nitrogen 5 . In this position, the delocalization of the positive charge was possible on the whole guanidine portion (see Figure 4). If the protonation happened on nitrogens in position 1 and 7, TBD would be a much weaker base, like ternary amines. The formed hydroxide anions were able to be exchanged against other anions (such as $\mathrm{Cl}^{-}$).
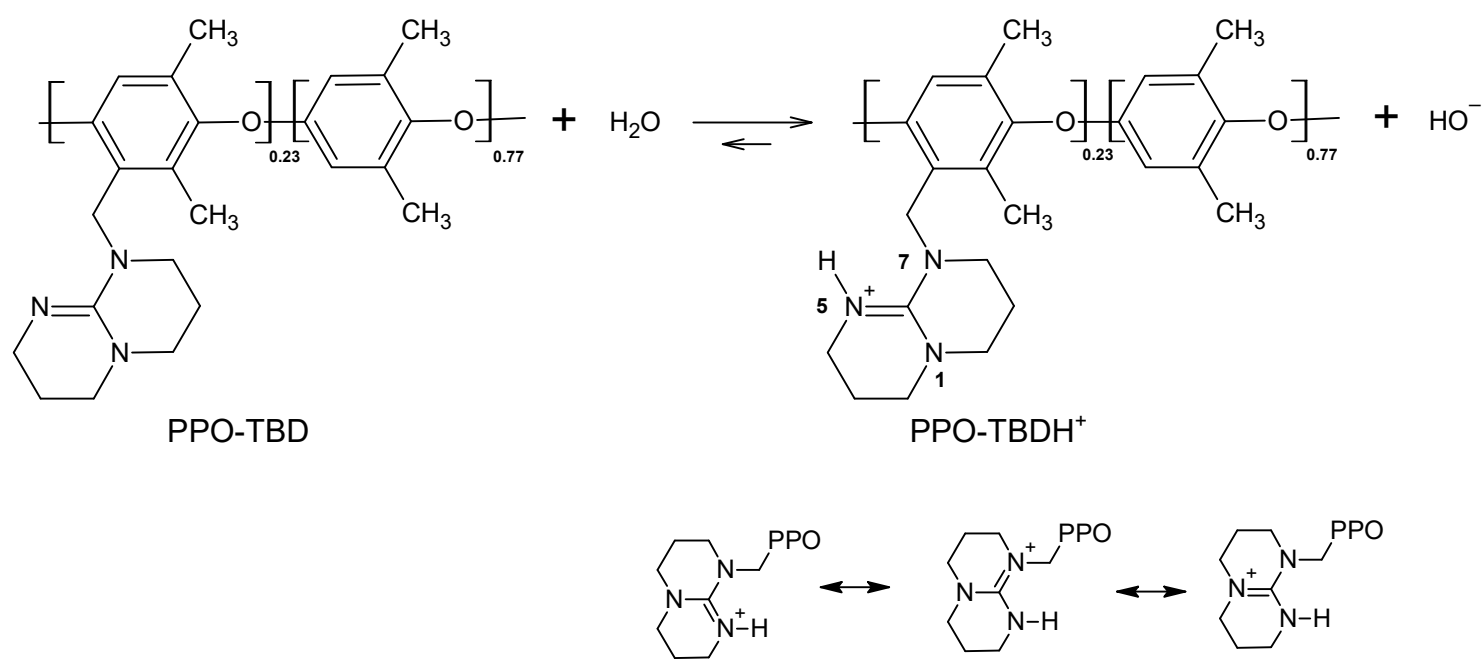

Figure 4. Dissociation acid-base equilibrium of PPO-TBD.

In comparison, the quaternized PPO-TBD-Me samples may present $100 \%$ free hydroxide anions, but only if the ion pairs are broken, for example in diluted solution. At high water uptake, the concentration of mobile anions can therefore be up to $20 \%$ higher, which should be observable in conductivity. 
Concerning the possible parasitic reactivity of TBD with $\mathrm{CO}_{2}$ gas, TBD grafted on a substrate, such as silica [34] or PPO in this work, lost the hydrogen atom of the secondary amine so that carbamate formation is impossible. Carbon dioxide can be bound only by relatively weak Van der Waals interactions, which can be easily overcome. In fact, low $\mathrm{CO}_{2}$ absorption rates make tertiary amines difficult to use for $\mathrm{CO}_{2}$ gas removal [38].

The ionic conductivity of both ionomers in chloride form is reported in Table 2. The interesting concept of an "intrinsic" ionic conductivity by the dissociation of the strongly basic TBD molecule is demonstrated. Given the large difference of ionic mobility between chloride and hydroxide ions, the $\mathrm{OH}^{-}$conductivity is predicted to be above $1 \mathrm{mS} / \mathrm{cm}$ at $20^{\circ} \mathrm{C}$. The chloride ion conductivity of the quaternized PPO-TBD-Me is quite high. The difference is larger than expected given the only slightly higher concentration of mobile anions in PPO-TBD-Me. The higher hydration numbers of PPO-TBD-Me are certainly increasing the anion mobility, as previously reported for other proton- and anion-conducting polymers [10,39-41]. Furthermore, one can assume a better nanophase separation in quaternized PPO-TBD-Me, due to the permanent ionic charges. The activation energy is very similar for both ionomers, around $0.2 \mathrm{eV}$.

Table 2. Ionic conductivity of PPO-TBD and PPO-TBD-Me ( $\mathrm{Cl}^{-}$form) in fully humidified conditions.

\begin{tabular}{ccc}
\hline \multirow{2}{*}{ T $\left({ }^{\circ} \mathrm{C}\right)$} & PPO-TBD & PPO-TBD-Me \\
\cline { 2 - 3 } & \multicolumn{2}{c}{$\mathbf{~ m S / c m}$} \\
\hline 20 & 0.5 & 4.2 \\
40 & 0.8 & 4.8 \\
60 & 1.0 & 7.5 \\
80 & 1.3 & 11.4 \\
\hline
\end{tabular}

\section{Conclusions}

The concept of "intrinsic" ionic conducting polymers formed by grafting strongly basic 1,5,7-triazabicyclo[4.4.0]dec-5-ene (TBD) on PPO macromolecules is explored and validated. The ionic conductivity of PPO-TBD is of the order of $1 \mathrm{mS} / \mathrm{cm}$ and the membranes are stable during long treatments in water at $60{ }^{\circ} \mathrm{C}$. The more classical quaternized PPO-TBD-Me samples show an even higher ionic conductivity of above $10 \mathrm{mS} / \mathrm{cm}$ at $80{ }^{\circ} \mathrm{C}$. These large values are attributed to the larger hydration and better nanophase separation, due to the presence of permanent ionic charges. Thermogravimetric measurements show that both PPO-TBD and PPO-TBD-Me are thermally stable up to $200{ }^{\circ} \mathrm{C}$.

Author Contributions: Conceptualization, M.L.D.V.; Methodology, R.N., G.E., R.A.B.-A., L.P., P.K. and M.L.D.V.; Validation, R.N.; Investigation, R.N., G.E., R.A.B.-A., L.P., P.K. and M.L.D.V.; Writing-original draft preparation, P.K. and M.L.D.V.; Writing—review and editing, R.N., G.E., R.A.B.-A., L.P., P.K. and M.L.D.V.

Funding: This research received no external funding.

Conflicts of Interest: The authors declare no conflict of interest.

\section{References}

1. Merle, G.; Wessling, M.; Nijmeijer, K. Anion exchange membranes for alkaline fuel cells: A review. J. Membr. Sci. 2011, 377, 1-35. [CrossRef]

2. Wang, Y.; Chen, K.S.; Mishler, J.; Cho, S.C.; Adroher, X.C. A review of polymer electrolyte membrane fuel cells: Technology, applications, and needs on fundamental research. Appl. Energy 2011, 88, 981-1007. [CrossRef]

3. Couture, G.; Alaaeddine, A.; Boschet, F.; Ameduri, B. Polymeric materials as anion-exchange membranes for alkaline fuel cells. Prog. Polym. Sci. 2011, 36, 1521-1557. [CrossRef]

4. Park, E.J.; Kim, Y.S. Quaternized aryl ether-free polyaromatics for alkaline membrane fuel cells: Synthesis, properties, and performance-A topical review. J. Mater. Chem. A 2018, 6, 15456-15477. [CrossRef] 
5. Pan, Z.F.; An, L.; Zhao, T.S.; Tang, Z.K. Advances and challenges in alkaline anion exchange membrane fuel cells. Prog. Energy Combust. Sci. 2018, 66, 141-175. [CrossRef]

6. Vijayakumar, V.; Nam, S.Y. Recent advancements in applications of alkaline anion exchange membranes for polymer electrolyte fuel cells. J. Ind. Eng. Chem. 2019, 70, 70-86. [CrossRef]

7. Hickner, M.A.; Herring, A.M.; Coughlin, E.B. Anion Exchange Membranes: Current Status and Moving Forward. J. Polym. Sci. Part B Polym. Phys. 2013, 51, 1727-1735. [CrossRef]

8. Hugar, K.M.; Kostalik, H.A.; Coates, G.W. Imidazolium Cations with Exceptional Alkaline Stability: A Systematic Study of Structure-Stability Relationships. J. Am. Chem. Soc. 2015, 137, 8730-8737. [CrossRef]

9. Marino, M.G.; Kreuer, K.D. Alkaline Stability of Quaternary Ammonium Cations for Alkaline Fuel Cell Membranes and Ionic Liquids. ChemSusChem 2015, 8, 513-523. [CrossRef] [PubMed]

10. Pasquini, L.; Di Vona, M.L.; Knauth, P. Effects of anion substitution on hydration, ionic conductivity and mechanical properties of anion-exchange membranes. New J. Chem. 2016, 40, 3671-3676. [CrossRef]

11. Sun, Z.; Pan, J.; Guo, J.N.; Yan, F. The Alkaline Stability of Anion Exchange Membrane for Fuel Cell Applications: The Effects of Alkaline Media. Adv. Sci. 2018, 5, 11. [CrossRef] [PubMed]

12. Han, J.J.; Pan, J.; Chen, C.; Wei, L.; Wang, Y.; Pan, Q.Y.; Zhao, N.A.; Xie, B.; Xiao, L.; Lu, J.T.; et al. Effect of Micromorphology on Alkaline Polymer Electrolyte Stability. ACS Appl. Mater. Interfaces 2019, 11, 469-477. [CrossRef] [PubMed]

13. Liang, M. Poly(phenylene oxide). In Handbook of Engineering and Specialty Thermoplastics; Thomas, S., Visakh, P.M., Eds.; Scrivener Publishing LLC: Beverly, MA, USA, 2011; Volume 3, pp. 15-54.

14. Arges, C.G.; Wang, L.H.; Parrondo, J.; Ramani, V. Best Practices for Investigating Anion Exchange Membrane Suitability for Alkaline Electrochemical Devices: Case Study Using Quaternary Ammonium Poly(2,6-dimethyl 1,4-phenylene)oxide Anion Exchange Membranes. J. Electrochem. Soc. 2013, 160, F1258-F1274. [CrossRef]

15. Mohanty, A.D.; Tignor, S.E.; Krause, J.A.; Choe, Y.K.; Bae, C. Systematic Alkaline Stability Study of Polymer Backbones for Anion Exchange Membrane Applications. Macromolecules 2016, 49, 3361-3372. [CrossRef]

16. Amel, A.; Yitzhack, N.; Beylin, A.; Pan, J.; Hickner, M.A.; Ein-Eli, Y. Chemical and Thermal Stability of Poly(phenylene oxide)-Based Anion Exchange Membranes Containing Alkyl Side Chains. J. Electrochem. Soc. 2018, 165, F1133-F1138. [CrossRef]

17. Dang, H.S.; Jannasch, P. Exploring Different Cationic Alkyl Side Chain Designs for Enhanced Alkaline Stability and Hydroxide Ion Conductivity of Anion-Exchange Membranes. Macromolecules 2015, 48, 5742-5751. [CrossRef]

18. Dang, H.-S.; Jannasch, P. A comparative study of anion-exchange membranes tethered with different hetero-cycloaliphatic quaternary ammonium hydroxides. J. Mater. Chem. A 2017, 5, 21965-21978. [CrossRef]

19. Pan, J.; Han, J.J.; Zhu, L.; Hickner, M.A. Cationic Side-Chain Attachment to Poly(Phenylene Oxide) Backbones for Chemically Stable and Conductive Anion Exchange Membranes. Chem. Mater. 2017, 29, 5321-5330. [CrossRef]

20. Xu, Y.X.; Ye, N.Y.; Zhang, D.J.; Yang, Y.F.; Yang, J.S.; He, R.H. Imidazolium functionalized poly(aryl ether ketone) anion exchange membranes having star main chains or side chains. Renew. Energy 2018, 127, 910-919. [CrossRef]

21. Hossain, M.M.; Hou, J.Q.; Wu, L.; Ge, Q.Q.; Liang, X.; Mondal, A.N.; Xu, T.W. Anion exchange membranes with clusters of alkyl ammonium group for mitigating water swelling but not ionic conductivity. J. Membr. Sci. 2018, 550, 101-109. [CrossRef]

22. Chempath, S.; Einsla, B.R.; Pratt, L.R.; Macomber, C.S.; Boncella, J.M.; Rau, J.A.; Pivovar, B.S. Mechanism of tetraalkylammonium headgroup degradation in alkaline fuel cell membranes. J. Phys. Chem. C 2008, 112, 3179-3182. [CrossRef]

23. Arges, C.G.; Ramani, V. Two-dimensional NMR spectroscopy reveals cation-triggered backbone degradation in polysulfone-based anion exchange membranes. Proc. Natl. Acad. Sci. USA 2013, 110, 2490-2495. [CrossRef]

24. Long, H.; Kim, K.; Pivovar, B.S. Hydroxide Degradation Pathways for Substituted Trimethylammonium Cations: A DFT Study. J. Phys. Chem. C 2012, 116, 9419-9426. [CrossRef]

25. Vega, J.A.; Chartier, C.; Mustain, W.E. Effect of hydroxide and carbonate alkaline media on anion exchange membranes. J. Power Sources 2010, 195, 7176-7180. [CrossRef] 
26. Di Vona, M.L.; Narducci, R.; Pasquini, L.; Pelzer, K.; Knauth, P. Anion-conducting ionomers: Study of type of functionalizing amine and macromolecular cross-linking. Int. J. Hydrog. Energy 2014, 39, 14039-14049. [CrossRef]

27. Coles, M.P. Bicyclic-guanidines, -guanidinates and -guanidinium salts: Wide ranging applications from a simple family of molecules. Chem. Commun. 2009, 25, 3659-3676. [CrossRef]

28. Kaljurand, I.; Kutt, A.; Soovali, L.; Rodima, T.; Maemets, V.; Leito, I.; Koppel, I.A. Extension of the self-consistent spectrophotometric basicity scale in acetonitrile to a full span of $28 \mathrm{pK}$ (a) units: Unification of different basicity scales. J. Org. Chem. 2005, 70, 1019-1028. [CrossRef] [PubMed]

29. Kiesewetter, M.K.; Scholten, M.D.; Kirn, N.; Weber, R.L.; Hedrick, J.L.; Waymouth, R.M. Cyclic Guanidine Organic Catalysts: What Is Magic About Triazabicyclodecene? J. Org. Chem. 2009, 74, 9490-9496. [CrossRef]

30. Di Vona, M.L.; Casciola, M.; Donnadio, A.; Nocchetti, M.; Pasquini, L.; Narducci, R.; Knauth, P. Anionic conducting composite membranes based on aromatic polymer and layered double hydroxides. Int. J. Hydrog. Energy 2017, 42, 3197-3205. [CrossRef]

31. Pizzoferrato, R.; Ciotta, E.; Ferrari, I.V.; Narducci, R.; Pasquini, L.; Varone, A.; Richetta, M.; Antonaroli, S.; Braglia, M.; Knauth, P.; et al. Layered Double Hydroxides Containing an Ionic Liquid: Ionic Conductivity and Use in Composite Anion Exchange Membranes. Chemelectrochem 2018, 5, 2781-2788. [CrossRef]

32. MacDonald, J.R. Impedance Spectroscopy: Emphasizing Solid Materials and Systems; Wiley: New York, NY, USA, 1987.

33. Lippert, T.; Wokaun, A.; Dauth, J.; Nuyken, O. NMR-studies of hindered rotation and thermal-decomposition of novel 1-aryl-3,3-dialkyltriazenes. Magn. Reson. Chem. 1992, 30, 1178-1185. [CrossRef]

34. Yu, K.M.K.; Curcic, I.; Gabriel, J.; Morganstewart, H.; Tsang, S.C. Catalytic Coupling of $\mathrm{CO}_{2}$ with Epoxide Over Supported and Unsupported Amines. J. Phys. Chem. A 2010, 114, 3863-3872. [CrossRef]

35. Ehlers, G.F.L.; Fisch, K.R.; Powell, W.R. Thermal degradation of polymers with phenylene units in the chain. I. Polyphenylenes and poly(phenylene oxides). J. Polym. Sci. Part A Polym. Chem. 1969, 7, 2931-2953. [CrossRef]

36. Li, X.G. High-resolution thermogravimetry of poly(2,6-dimethyl-1,4-phenylene oxide). J. Appl. Polym. Sci. 1999, 71, 1887-1892. [CrossRef]

37. Kaupmees, K.; Trummal, A.; Leito, I. Basicities of Strong Bases in Water: A Computational Study. Croat. Chem. Acta 2014, 87, 385-395. [CrossRef]

38. Chowdhury, F.A.; Yamada, H.; Higashii, T.; Goto, K.; Onoda, M. $\mathrm{CO}_{2}$ Capture by Tertiary Amine Absorbents: A Performance Comparison Study. Ind. Eng. Chem. Res. 2013, 52, 8323-8331. [CrossRef]

39. Knauth, P.; Sgreccia, E.; Donnadio, A.; Casciola, M.; Di Vona, M.L. Water Activity Coefficient and Proton Mobility in Hydrated Acidic Polymers. J. Electrochem. Soc. 2011, 158, B159-B165. [CrossRef]

40. Knauth, P.; Pasquini, L.; Maranesi, B.; Pelzer, K.; Polini, R.; Di Vona, M.L. Proton Mobility in Sulfonated PolyEtherEtherKetone (SPEEK): Influence of Thermal Crosslinking and Annealing. Fuel Cells 2013, 13, $79-85$. [CrossRef]

41. Knauth, P.; Di Vona, M.L. Sulfonated aromatic ionomers: Analysis of proton conductivity and proton mobility. Solid State Ion. 2012, 225, 255-259. [CrossRef]

(C) 2019 by the authors. Licensee MDPI, Basel, Switzerland. This article is an open access article distributed under the terms and conditions of the Creative Commons Attribution (CC BY) license (http://creativecommons.org/licenses/by/4.0/). 